\title{
The Soft law Governance Research of Grassroots Community--in Terms of Strangers Becoming Acquaintance in a Society
}

\author{
Xiang Wang \\ School of Law, Xiamen University, Xiamen 361000, China; \\ wangxiangjustin@163.com
}

Keywords: Community, Governance, Strangers' Society, Acquaintances, Softlaw.

\begin{abstract}
The premise of the proposition of rule of law is always that we are living in a society made of strangers. However the Chinese traditional society was made of acquaintances, where the social regulation is suitable for the relationship between acquaintances. Nowadays, the Chinese traditional governance mode has given us several valuable experiences about establishment of social rule of law. In the process of the localization of the proposition of rule of law, it is an important approach of social governance innovation through converting strangers into acquaintances in a society, especially in a community. Based on the research of several communities of Haiyang district in Xiamen, it can be found that the rule of soft law is the internal principle of social governance by converting strangers into acquaintance.
\end{abstract}

\section{Problem Presentation}

\subsection{Rule of Law Based on Strangers Society?}

Legal science always thinks that the modern rule of law should be made based on strangers' society. A society made of acquaintance doesn't need legal and court, because when neighborhood disputes, they usually resort to tradition and habits to solve divergence. "Modern legal culture has its own unique social 'context', which is a strangers' society. A strangers' society needs urban as space of activities and citizens as members." Since Chinese reform and opening, social transformation and the rapid development of market economy has been breaking the regional factors on the limit of the individual. With the increase of population mobility, the autonomy of people has been increasing. As a result people gradually completed the transition from the "identity" to "contract", and the social characteristics of strangers in big cities is more and more obvious. But the rule of law order and the legal effect in these areas are still not very impeccable. There are various reasons, which includes that the high cost of law is more than the possible benefits of settling disputes; the low quality law can't agree with practice needs, etc. In general, the tentacles of law are not able to extend in a good way to grassroots communities. To start from the Macro-view, compared with the past, our society has been showing a tendency of complication and diversification. All aspects of the governance of grassroots is filled with uncertainty and unpredictability, thus the "the unified central authority apparently unable to make norms covering all areas and considering to all the related factors of detailed rules. Control and command structure is no longer possible, feasible and effective." Concentrating on the micro level, it is apparently that many community management problem has been not solved very well, which still has huge institutional space. Therefore, it is a way to fill the system space transforming from simple "management" of hard law to the concept of "governance" of softlaw, which is also a feasible way to solve the problem of the present community governance. As grassroots autonomous organizations, communities are taking a lot of work in the process of daily operation. In order to "finish" tasks, grassroots communities are good at spontaneously exploring the effective mechanism and measures to solve the problem, which is significance for the production and operation of soft rules. Therefore, this topic is focus on researching softlaws and regulations and significance spontaneously generated in the process of governance in the grassroots community. For the community filled with the Migrant Population, the core of softlaw governance is that making a society full of acquaintances instead of strangers. 


\subsection{Definition}

\subsubsection{The Community And The Community of The Migrant Population}

In 1881, The German word gemeinschaft (i.e., the community, group, collective, communities, community, etc.) was firstly used in sociology by the German sociologist Feeding Tennis .And then in 1887, the German sociologist Feeding Tennis initiated the community analyzing system in his book Community and Society published in 1887, in which he analyzed gemeinschaft and gesellschaft (generally translated into social) in comparison. As a external form, a community is characterized by a family, village and town, and a society is characterized by a big city, capital and urban city in the world. In the United States, with the rapid development of industrialization, a group of big cities such as New York, Chicago appeared in the east and the north. Chicago was especially the most outstanding with its rapid development. In the process of rapid development, Chicago simultaneously faced poverty, crime and crowded population called "city disease". In such historical conditions, the "Chicago school introduced Tennis's community concept to study in American society." Unlike Tennis contrasting community with society, the Chicago school did not put community in opposition to society, instead it studied a community as a part of a society.

American academic achievements had directly affected the community research in China. According to Fei Xiaotong's memories, the concept of "community" is the earliest translated by a group of students at the Yenching University from Parker's word "Community". Fei Xiaotong and some others thought the society's "club" meant a crowd, "zone" meant located space of a group, and they created a new Chinese word to explain the "Communit" by figuring Parker's Human Ecology out. Apparently the word "community" first appeared in China, it has the connotation of regional.

The above relates to understanding of the meaning of the community by early scholars in the west and China. However, nowadays, the community research started from reform and opening in China. The concept of "community" began to be officially used by Chinese in the late $1980 \mathrm{~s}$, and large numbers of laws, administrative regulations, local regulations and local government regulations on "community" has made different regulations. Although rules emerged in endlessly, but there was hardly any clear definition of "community". On December 18, 2000, Central Committee General Office and State Council issued "The ministry of civil affairs on promoting the construction of urban community in the country", which proclaimed that "community means a social live community within the scope of people congregating in certain region. Currently the urban community generally includes the residential committee districts which has been adjusted the scale after the reform for the system of communities." This document regulated the regional scope of the community specifically which is a kind of the concept of administrative divisions. Afterward the Chinese communities include not only the residential areas, but also enterprises, different institutions and even the mall. In practice, "Community of the Migrant Population "is one of concept that is usually used to refer to the higher percentage of Migrant Population of the community. Because of the high liquidity, characteristics of strangers' society in this kind of community is more apparent.

\subsubsection{Softlaw and Volklaw}

What is a softlaw? There are many different views in academic fields. French scholar Francis Snyder said: "in principle softlaw has no legally binding, but it has actual effectiveness of rules of behavior." Based on summarizing the view of domestic and foreign scholars, some scholars have shown the extension of softlaw. There are totally 12 kinds of expressive forms of softlaw. Some other scholars think the extension of softlaw shall be limited to the following:(1) the industrial associations, institutions of higher education and other social autonomous organizations regulations of its own organization and activities and constitutions, rules, principles of group behavior;(2) the regulations of grassroots autonomous organization and activities and the constitutions, rules, principles of the behaviors of members, such as village regulations, etc.;(3) the regulations of organizations and activities of CPPCC and PO and the constitutions, rules, principles of the behaviors of members, and the externally effective programmes, norms made by CPPCC when it acts on NPC;(4) the regulations of organizations and activities of international organizations and constitutions, rules, principles of behaviors of members;(5) clauses without clear legal liability in the laws, regulations and rules;(6) the 
regulations of organizations and activities of ruling party and participatory party and constitutions, rules, principles of behaviors of members.

Folklaw is related to softlaw. Strictly so-called folklaw "is the amplectant legal interpretation of folk custom and ethical rules in the context of legal pluralism", and "does not have the basic characteristic of the legal norms". However, through the transformation of the mechanism of softlaw and utilizing the initiative convenience and flexibility of soft law, folk customs and a series of high quality traditional system resources can be converted into softlaw, which is supplemented with hard law and makes up the short board of system of the governing of rules, solving practical problems. Meanwhile, based on the existed legitimacy of partly recognition of the folk law, through the re-creation by softlaw mechanism, it can enrich legitimacy foundation of state law and provide the contradiction of the existing system and realistic problem with buffered theory space.

\section{The Present Situation of Familiarity in The Community Residents}

In September 2015, I took a month to research in Xingwang community, Xiayang community and Xianglu community in Xinyang Street. When I helped the community staff work, I interviewed to the staff and residents, getting materials and the information of this article. Understanding the research location and theme I designed questionnaires, which was modified and sent out with the consent of staff of the community and street. I totally gave out 300 questionnaires, recovered 287 questionnaires including 266 valid questionnaires. And then the data of interviews and questionnaires were analyzed and by me who wrote research reports. April to May in 2016, through the discussion with relevant staff I made the supplement investigation for solving new problems founded in the written research report.

There were more female accounted for about $60 \%$ of the total filling in the questionnaire than men accounted for about $40 \%$ of the total. In the age structure, respondents were mostly middle-aged and young, people between the ages of 21 to 30 accounted for about $35.85 \%$ of the total, people between the ages of 31 to 40 accounted for $28.3 \%$ of the total, both accounting for $64.15 \%$ of the total, people who was older than 50 accounted for only $9.05 \%$ of the total. On accommodation problem, about $83.47 \%$ of the respondents said they were renting houses, only $16.53 \%$ of respondents said they owned houses, and this one aspect demonstrated the characteristics of the foreign population in the survey places. In the cultural degree, respondents were mostly got only junior high school diploma or lower, which is accounted for $53.26 \%$ of the total, some others got bachelor degree and above in only $4.98 \%$ of the total.

Through the questionnaire data analysis, residents in Xinyang Street were not familiar with each other. When asked "are you familiar with neighbors in the same floors upstairs or downstairs", only $10.65 \%$ of residents said they were very familiar with the neighbors in the same floor upstairs and downstairs; $28.9 \%$ of residents said they were just familiar with the neighbors in the same floor upstairs and downstairs; $37.26 \%$ of residents said their neighbors were nodding acquaintances, just know them; And nearly a quarter of the residents directly said they did not recognize with the neighbors. As the diagram below:

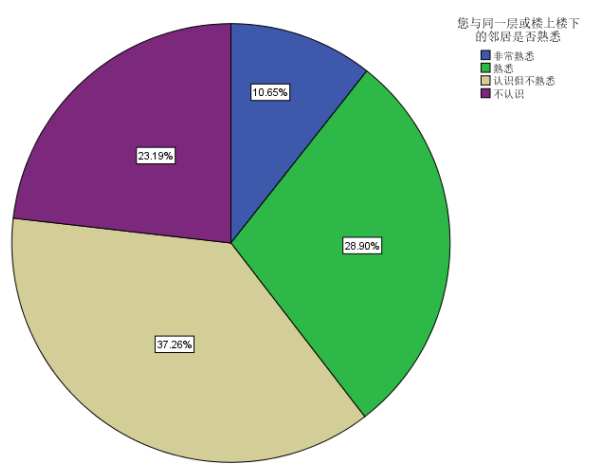

Figure 1: if you are familiar with neighbors in the same floor upstairs or downstairs

On the relationship with other residents in the same community, residents' familiarity degree between each other was also very low. When asked "if you are familiar with other residents in the same 
community", only $5.04 \%$ of residents said they were very familiar; $24.03 \%$ said they knew each but not familiar; $29.46 \%$ of residents they did not know other residents in the community. As the diagram below:

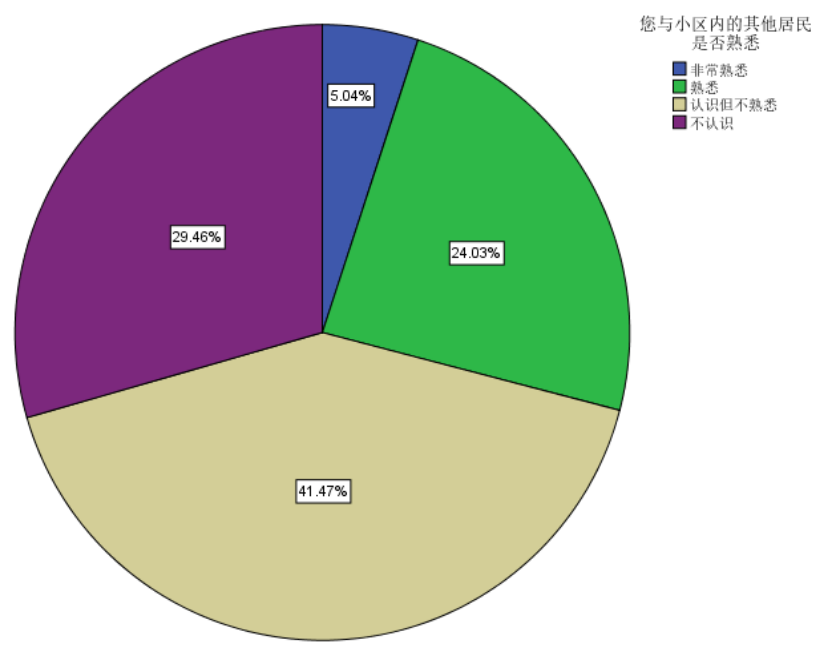

Figure 2: if you are familiar with other residents in the community

Therefore, in daily activities, the familiarity of community residents with each other were not high either with neighbors in the same floor or with the others there. In general, only about $40 \%$ of residents said they were familiar with neighbors, and less than $30 \%$ of residents said they were familiar with other residents in the community. Even the inhabitants familiar with each other, have short chatting time in average weekly. Subjectively, the respondents' willingness and enthusiasm in taking participation in community activities to meet the neighbors was not high. But in the workplaces, respondents said they were familiar with the colleagues, residents with more than familiarity accounted for $75.82 \%$ of the total number of samples. It had provided familiarity of the field of the residents living with reference and experiences. Because familiarity among community residents is the important condition of residents in the community identity, which also is the key to governance community well.

\section{The Softlaw Mechanism in The Process of Becoming Acquaintances}

The communities in Xinyang Street is a microcosm of the urban grassroots community in China. Chinese society has gradually become strangers' society. In the urban community, people may live with strangers in the same corridor. From morning to evening people never had any contact with their neighbors. In such a society, social bonds may rupture easily, thus leading to problems such as social disorder, moral anomie and lack of awareness of community. Promoted measures of being acquaintances embodies the principle of softlaw governance. Xinyang Street took series of measures to converting the strangers' society into acquaintances', which is mainly due to motivating everyone to participate and interact. Currently the trend of the community governance is becoming to a complex management, which means that various community topics, such as the party organizations, neighborhood committees, service stations, community social organizations, community residents and district units, etc., based on the public interests and community identity, through coordination and cooperation, do the best in providing the community with public service, optimizing the community order, promoting the public interest, improving public interests. Through cooperation of the five groups and six main parts, people can establish a community governance mode including unified leadership of the party organization, legal autonomous community organizations, public services provided by service community platform, effective coordination of community social organizations, coordination between the units and residents who widely participate in. This multiple interactive governance mode also reflected the concepts of softlaw including the openness, democracy, participation and negotiation. For governments, the benefits of participation are they can entrust organization and citizens, which is community autonomy and have professional knowledge and 
technology, with some affairs that they shouldn't manage, or manage badly. They only need to provide policy support and guidance about requirements. As Rosabeth Moss Kante said: "seeking for the community is seeking collective orientation direction of personal life and the pursuit of goals. To put yourself into a community, with identity of the authority of a community and willing to support the life of the community, all of this can provide identity, personal will, and growth opportunities in accordance with the members wanted to express his own internal quality standards and guiding principles." For social organizations, it is benefited from participation that they can improve the ability of organization construction as much as possible, provide quality social services, maintain good operation of organizations, access to a high level of social evaluation, thus "growth" during participation.

During promoting the formation of acquaintances many soft rules have been made. In general, without the compulsory execution by the court, softlaw does not have legally bindings as hard law, but this does not mean that softlaw does not have any effect or no legally binding. In some cases, the effectiveness of softlaw on the control effect makes the actual binding may be stronger than hard law. In governance practices of the Xinyang Street, indeed the soft rules had a good governance effect. So far, softlaw norms of the Xinyang street mainly include: the Xinyang street "Management Interim Measures of 'New Xiamen Residents' Base of Incubating Social Organizations"”, "Interim Measures for supporting social organizations of Xinyang street community" and "Interim Measures for the record management of Xinyang street community social organizations for ", "Interim Measures for venture philanthropy project management of Xinyang street", "methods on venture philanthropy project evaluation of Xinyang street (trial)", etc. Communities also established some soft law norms, such as residents' autonomy regulations, measures for building management and building convention.

Many problems can be easily resolved through the softlaw instead of being unreached or solved by law badly. As a supplement for governance by hard law, the significance of the governance of softlaw has not been yet fully excavated.As the bottom of the community, its importance is seldom respected by people. In the grassroots community, the exploration of softlaw governance has begun quietly. Staff in the grassroots community may hardly know what "softlaw" is, and also don't know they took measures in order to pursuing their own problem-solving is of softlaw significance, but the practice was innovative and creative. This is not to say that the grassroots community was perfect in the process of exploring the softlaw governance, but we should pay attention to the trends and implications shown in the outstanding practice in grassroots community. In my opinion, the grassroots community's practice means more than that, as softlaw governance is a complementary of the governance of hard law, also is the key to unlock the present dilemma of rule of law. The exploring process of practices on softlaw governance in a grassroots community is actually the process of the rule of law to seek a way out for China.

\section{References}

[1]. Zhang Qing, Wang Lu. Theory and Strategy of Strangers 'Societies and the Establishment of Rule of Law. ZUEL Law Journal. (2008) No. 5.

[2]. Chen Guang. On the Relationship and Cohesion between Soft and Hard Law in Community Governance. Journal of Gansu Political Science and Law Institute. (2013) No. 4.

[3]. Li Rongshan. The Fate of the Community -- From Herder to the Contemporary Change. Sociological Studies. (2015) No. 1.

[4]. Fei Xiaotong. The Introduction of the Social Self-governance. Society. (2000) No. 10.

[5]. Luo Haocai, Bi Honghai. Through governance of softlaw. The Jurist. (2006)No.1.

[6]. Jiang Mingan. The Rise and Rule of Softlaw. China Legal Science. (2006) No. 2.

[7]. Liang Jianbing. On the Coupling and Boundary between Softlaw and Folklaw. The Rule of Law Forum. (2009) No. 6. 
[8]. Zheng Hangsheng, Huang Jialiang. On the Double Predicament and Innovation of Community Governance in Our Country -- based on analysis of community management system reform practice in Beijing. Dongyue Tribune. (2012) No. 1.

[9]. Luo Haocai, et al. The Softlaw and Public Governance. Peking University Press. 2006. P.134.

[10]. Feeding Tennis. Community and Society. The Commercial Press. 1999. p.333-339. 